\title{
CARACTERIZAÇÃO DE RESÍDUOS CERVEJEIROS
}

\author{
T. R. S. MATHIAS ${ }^{1}$, P. P. M. de MELLO, ${ }^{2}$ e E. F. C. SERVULO ${ }^{1}$ \\ ${ }^{1}$ Universidade Federal do Rio de Janeiro, Escola de Química \\ ${ }^{2}$ SENAI, Centro de Tecnologia SENAI de Alimentos e Bebidas \\ E-mail para contato: thiago.rsmathias@gmail.com
}

\begin{abstract}
RESUMO - Os resíduos agro-industriais são produzidos em grandes quantidades, em todo o mundo, a partir do beneficiamento e industrialização de alimentos. $\mathrm{O}$ descarte desses resíduos no meio ambiente resulta em uma série de transtornos para o ecossistema, devido à sua rica composição em matéria orgânica. Neste contexto, pode se destacar a indústria cervejeira, cuja produção inclui etapas de processamento e fermentação de matéria-prima vegetal, como cevada, lúpulo e outros grãos utilizados como adjuntos, gerando diferentes subprodutos. Devido às características de composição dos resíduos cervejeiros, estes apresentam significativo potencial para aplicação em tecnologias de bioprocessos. O presente trabalho teve por objetivo a caracterização de três resíduos cervejeiros sólidos, a saber, bagaço de malte, trub quente e levedura residual cervejeira, em função dos teores de umidade, cinzas, açúcares redutores, e proteínas totais e solúveis. Os três resíduos avaliados apresentaram elevado teor de umidade e significativa fração protéica, evidenciando a possibilidade de sua utilização para recuperação desta.
\end{abstract}

\section{INTRODUÇÃO}

A cerveja é uma bebida alcoólica milenar obtida como produto da fermentação do mosto de cereal malteado (cevada), acrescido ou não de outros cereais ou fontes de açúcares, denominados adjuntos, com adição de lúpulo, por ação de leveduras (Tschope, 2001; Rehm e Reed, 1983). Por muitos séculos a produção de cerveja em escala artesanal era suficiente para suprir toda a demanda, produzindo-se cervejas de grande variedade e boa qualidade. Contudo, a grande difusão e aceitação desta bebida ao longo de sua história levaram a cerveja a ser uma das bebidas mais apreciadas e consumidas nos cinco continentes, em países de diferentes climas e culturas. Atualmente, a produção em grandes escalas, para atender a grande demanda do produto, caracteriza o mercado cervejeiro mundial, levando à geração de grandes quantidades de resíduos.

\subsection{Resíduos Cervejeiros}

Diversos avanços tecnológicos têm proporcionado à indústria cervejeira grandes economias pela menor geração de subprodutos ao longo do processo. Contudo, certos resíduos intrínsecos à produção da bebida dificilmente têm redução de sua quantidade gerada, como o bagaço de malte, o trub e a levedura residual cervejeira. Estes resíduos são responsáveis pela perda de aproximadamente $20 \mathrm{de}$ cada $100 \mathrm{~L}$ de da água cervejeira utilizada no processo, principalmente pelo elevado teor de umidade que os compõe, entre 80 e $90 \%$, promovendo grande arraste de mosto e perda de extrato, bem como 


\section{9 a 22 de outubro de 2014 \\ Florianópolis/SC}

de cerveja, a depender da fase em que o resíduo é retirado, o que acarreta a geração de significativas quantidades de efluentes (Priest e Stewart, 2006).

O bagaço de malte é gerado após a etapa de mostura e esgotamento dos grãos de malte moídos, quando já foram extraídos todos os compostos solúveis de interesse para constituição do mosto doce e sua clarificação, durante a qual o bagaço exerce importante papel como torta filtrante. Este resíduo constitui o resíduo sólido de maior quantidade gerado no processo cervejeiro (cerca de $85 \%$ do total), sendo produzido em grandes volumes ao longo de todo ano, com baixo ou sem custo algum para sua aquisição, apresentando elevado valor nutricional (Aliyu e Bala, 2011; Lima, 2010). Em geral, para cada $100 \mathrm{~kg}$ de grãos processados, são gerados 125 a $130 \mathrm{~kg}$ de bagaço úmido, com cerca de $80 \mathrm{a}$ $85 \%$ de umidade, o que corresponde a cerca de 14 e $20 \mathrm{~kg}$ de bagaço para cada hectolitro de cerveja produzida (Fillaudeau et al., 2006).

O trub quente é o segundo resíduo sólido gerado no processo cervejeiro, durante a etapa de cocção do mosto. É resultante, predominantemente, da coagulação de proteínas, principalmente de elevada massa molar, cujas moléculas tendem a perder água de solvatação por ação do calor, o que promove sua desnaturação. Contudo, outras substâncias podem estar presentes, devido à sua participação na formação destes complexos ou devido ao arraste durante sua deposição. Além da coagulação protéica, a presença de cátions, principalmente $\mathrm{Ca}^{2+}$, de compostos do lúpulo que apresentam baixam eficiência de solubilização, de polifenóis e de carboidratos não totalmente hidrolisados na mostura, também irão influenciar a formação do trub (Priest e Stewart, 2006; Barchet, 1993). Em geral, formam-se entre 0,2 e $0,4 \mathrm{~kg}$ de trub úmido (80 a $90 \%$ de umidade) para cada hectolitro de cerveja produzida (Briggs et al., 2004).

A levedura cervejeira é o bioagente responsável pela conversão do mosto em cerveja. Em geral, durante a etapa de fermentação, a massa de levedura tende a se multiplicar entre 3 e 5 vezes no reator (Briggs et al., 2004). Quando a fermentação é encerrada, segue-se um período de repouso à baixas temperaturas, durante o qual ocorre a precipitação da grande massa de células, que deve ser removida. Prática comum da indústria cervejeira é reutilizar a massa de células geradas para inoculação de novos tanques de fermentação, contudo, há limitação do número de reutilizações, de forma a manter a qualidade da bebida. Dessa maneira, ao se esgotar a possibilidade de reciclo de células, estas devem ser eliminadas do processo, gerando novo resíduo sólido, que ocupa o segundo lugar em volume de produção, em torno de 1,5 e $3 \mathrm{~kg}$ (com 85 a 90\% de umidade) para cada $100 \mathrm{~L}$ de cerveja produzida (Olajire, 2012; Ferreira et al., 2010; Fillaudeau, et al., 2006).

\subsection{Potenciais Aplicações}

Devido aos resíduos cervejeiros apresentarem uma rica composição em compostos orgânicos e com significativo poder nutricional, devem ser tratados antes de dispensados ao ambiente, de forma a evitar alterações ao equilíbrio ecológico local. Dessa maneira, há grande incentivo à redução da geração de resíduos ou seu aproveitamento em outros processos. Nesse aspecto, visando à obtenção de produtos de maior valor agregado e a destinação dos resíduos gerados para fins mais nobres, os bioprocessos industriais apresentam-se como potenciais meios para destinação destes rejeitos (Pandey et al., 2001), além de suas possíveis aplicações em alimentação animal e humana. 


\section{9 a 22 de outubro de 2014 \\ Florianópolis/SC}

O bagaço de malte é predominantemente fibroso (70\% massa seca) e protéico (15 a $25 \%$ massa seca), apresentando também em sua composição lipídeos, minerais, vitaminas, aminoácidos e compostos fenólicos (Aliyu e Bala, 2011; Lima 2010; Robertson et al., 2010; Mussato et al., 2006). Destino usual é a venda para elaboração de ração animal. Segundo Aliyu e Bala (2011), Mussato e colaboradores (2006) e Lima (2010), diversas aplicações podem ser citadas, como: alimentação e nutrição animal e humana; produção de energia por queima direta ou por produção de biogás via fermentação anaeróbia; produção de carvão vegetal; material adsorvente em tratamentos químicos; cultivo de micro-organismos e obtenção de bioprodutos por fermentação; suporte para imobilização celular; dentre outros.

O trub quente apresenta em sua composição predominantemente proteínas (entre 50 e $70 \%$ da massa seca), além de substâncias amargas do lúpulo (10 a 20\%), polifenóis, carboidratos, minerais e ácidos graxos (Barchet, 1993). Há poucos relatos na literatura à respeito deste resíduo; comumente é misturado ao bagaço de malte para recuperação de mosto cervejeiro na etapa de lavagem do bagaço e, posteriormente, destinado para elaboração de ração animal (Priest e Stewart, 2006).

A levedura residual também apresenta caráter protéico (entre 35 e $60 \%$ da massa seca), com destaque para o elevado valor nutritivo, devido à presença de aminoácidos essenciais em sua estrutura e de vitaminas do complexo B. Ademais, apresenta em sua composição carboidratos, minerais, lipídeos, enzimas e RNA (Pinto et al., 2013; Bekatorou et al., 2006). O atual maior destino da levedura residual cervejeira é para formulação de ração animal. Recentemente, novos destinos têm sido explorados, como a obtenção de produtos de elevado valor nutricional para a aplicação na indústria farmacêutica e na dieta humana, como suplementos alimentares, devido à sua rica composição e por ser geralmente reconhecida como "segura" (GRAS - generally recognized as safe) (Man-Jin, 2005; Briggs et al., 2004, Assis, 1996). Além das aplicações em alimentos, este resíduo ou seus derivados, como os extratos a partir dele obtidos, podem ser utilizados em processos biotecnológicos em geral, para obtenção de enzimas, principalmente a invertase, presente em sua parede celular (Hough, 1990), ou para suplementação de meios de cultivo, manutenção e de fermentação (Ferreira et al., 2010).

\section{MATERIAIS E MÉTODOS}

Obtenção e preparo dos resíduos cervejeiros: Os três resíduos avaliados neste trabalho, bagaço de malte, trub quente e levedura residual (Figura 1), foram obtidos em cervejaria de médio porte localizada no estado do Rio de Janeiro, imediatamente após o término de uma batelada de produção de cerveja pilsen tradicional. De modo a possibilitar armazenamento adequado, o material foi submetido à secagem em estufa a $65^{\circ} \mathrm{C}$.

Caracterização dos resíduos: O teor de umidade dos resíduos obtidos úmidos foi determinado por método direto em balança de infra-vermelho, a $105^{\circ} \mathrm{C}$, e o resíduo mineral fixo (cinzas), por incineração a $550^{\circ} \mathrm{C}$ (AOAC, 1975). O teor de proteínas totais foi determinado pelo método de Kjeldahl. $\mathrm{O}$ fator de conversão de nitrogênio em proteínas adotado foi de 6,25 para o bagaço de malte e o trub quente e de 5,8 para a levedura residual cervejeira. 

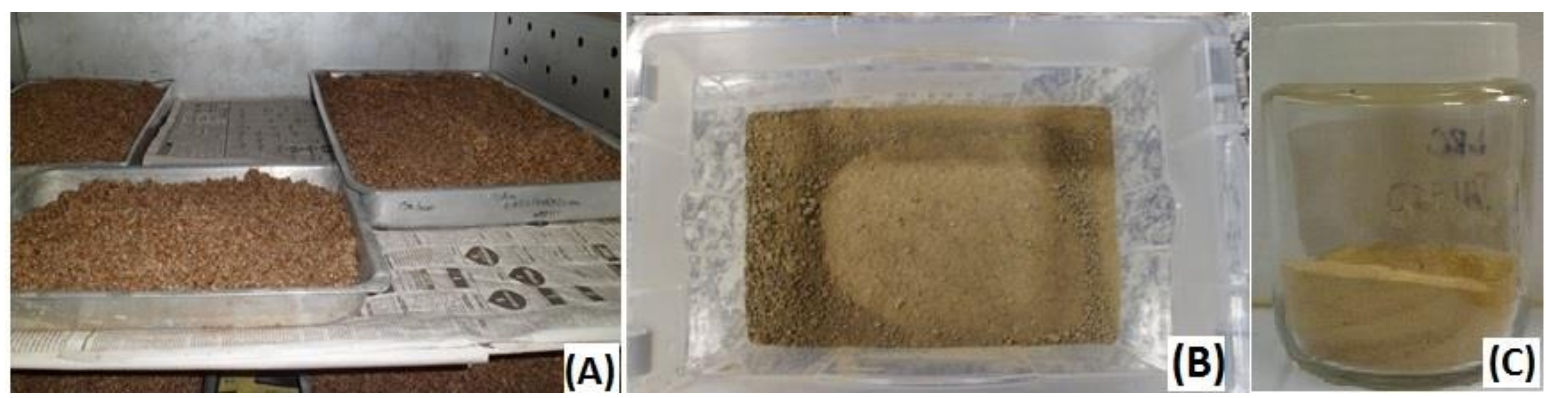

Figura 1 - Resíduos cervejeiros secos. (A): bagaço de malte; (B): trub quente; (C) levedura residual.

Para extração da fração solúvel, três amostragens de 2,5 g de cada resíduo foram realizadas. As amostras foram adicionadas de água destilada em um volume total de forma a se estabelecer uma concentração de aproximadamente $5 \%(\mathrm{~m} / \mathrm{V})$. Inicialmente, em bécheres de $100 \mathrm{~mL}$, contendo os resíduos sólidos devidamente pesados, foram adicionados $30 \mathrm{~mL}$ de água destilada e a mistura foi homogeneizada em agitador magnético por 30 minutos, para solubilização das frações. Em seguida, o material foi centrifugado sob refrigeração $\left(4^{\circ} \mathrm{C}\right)$, a $1370 \mathrm{~g}$ por 10 minutos e o sobrenadante foi recolhido. Ao precipitado, adicionaram-se $20 \mathrm{~mL}$ de água destilada e repetiu-se o procedimento de homogeneização e centrifugação. Após o recolhimento de toda a fração líquida, o material foi filtrado à vácuo em papel de filtro Whatman $\mathrm{n}^{\circ}$ 4. As amostras assim obtidas foram submetidas à determinação de proteínas totais pelo método de Kjeldahl e de açúcares redutores livres pelo método do DNS.

\section{RESULTADOS}

Os valores encontrados para os teores de umidade e cinzas do bagaço de malte analisado (Tabela 1) são coerentes com os dados da literatura. Santos e colaboradores (2003) avaliaram o teor de umidade e de cinzas de 8 lotes de bagaço cervejeiro, constituído de $80 \%$ de malte de cevada e $20 \%$ de milho, obtendo valores entre 76,8 e 78,9\%, para umidade, e entre 3,4 e 4\% para cinzas, em base seca. Zhaoxia e colaboradores (2012) encontraram o teor de água de $79 \%$ e de cinzas em 4,4\%, para o bagaço de malte seco proveniente de cervejarias comerciais. Robertson e colaboradores (2010) determinaram o teor de umidade presente em bagaços de malte de cevada provenientes de 10 cervejarias comerciais, e encontraram valores entre 75 e $80 \%$. Celus (2006) encontrou o teor de 3,3\% de cinzas para o bagaço obtido após mostura de malte de cevada puro. Em outros levantamentos bibliográficos de revisão, foram encontrados valores entre 2,3 e 7,9\% de cinzas e entre 75 e $85 \%$ de umidade na composição do bagaço de malte residual de cervejaria (Olajire, 2012; Aliyu e Bala, 2011).

O trub quente apresentou elevado teor de umidade e teor de cinzas inferior ao dos demais resíduos avaliados (Tabela 1), fato que pode ser justificado pela sua formação, predominantemente resultado da coagulação de proteínas de elevada massa molar que perdem água de solvatação em elevadas temperaturas (Barchet, 1993). Não foram localizados na literatura trabalhos experimentais que relatassem a determinação da composição do trub quente; apesar disto, alguns trabalhos de revisão ou livros indicam que o mesmo tem um percentual de umidade variando entre 80 e $90 \%$ 


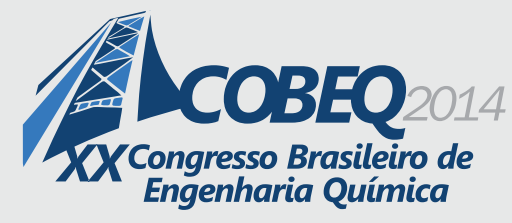

19 a 22 de outubro de 2014

Florianópolis/SC

(Olajire, 2012; Briggs et al., 2004; Hough, 1990) e o percentual de cinzas entre 3 e $5 \%$ (Priest e Stewart, 2006).

Tabela 1 - Composição dos resíduos cervejeiros

\begin{tabular}{|c|c|c|c|}
\hline & Bagaço de malte & trub quente & Levedura residual \\
\hline Umidade (\%) & $82,60 \pm 0,10$ & $86,90 \pm 0,10$ & $86,00 \pm 0,05$ \\
\hline Cinzas (\%) & $3,85 \pm 0,00$ & $2,00 \pm 0,08$ & $5,86 \pm 0,05$ \\
\hline ARS* (\%) & $0,65 \pm 0,05$ & $20,0 \pm 0,00$ & $1,3 \pm 0,00$ \\
\hline PT* (\%) $^{*} \%$ & 48,78 & 52,74 \\
\hline PS* (\%) & 26,89 & 0,88 & 14,66 \\
\hline
\end{tabular}

* ARS: açúcar redutor solúvel; PT: proteína total; PS: nitrogênio solúvel.

Para a levedura residual cervejeira em sua forma pastosa, como é normalmente chamada, depois de removida dos tanques de fermentação, os valores médios do teor de umidade e de cinzas (Tabela 1) estão de acordo a literatura revisada. Pinto e colaboradores (2013), encontraram valor médio de umidade de $74 \%$ para duas amostragens de levedura residual de cervejaria comercial, e valor ligeiramente inferior para o teor de cinzas, próximo a $2 \%$. Vilela e colaboradores (2000), utilizaram em seus estudos levedura residual de cervejaria, que também apresentou $80 \%$ de umidade e teor de cinzas de 7,9\%. Caballero-Cordoba e Sgarbieri (2000) e Costa e colaboradores (2012), encontraram percentual de cinzas ligeiramente mais elevados, de 8,5 e 6,98\%, respectivamente.

O teor de açúcares redutores obtido para o bagaço de malte $(0,65 \%)$ corrobora com os dados de literatura que indicam o bagaço de malte como material predominantemente fibroso (Aliyu e Bala, 2011; Lima 2010; Robertson et al., 2010; Mussato et al., 2006) e não rico em açúcares fermentáveis. Ademais, a lavagem até a exaustão deste resíduo para recuperação de extrato no mosto cervejeiro reduz ao máximo o teor de açúcares redutores presentes. $\mathrm{O}$ baixo valor de açúcares redutores solúveis encontrado para a levedura residual $(1,3 \%)$ também está de acordo com o esperado, uma vez que tal resíduo apresenta em sua maior proporção polissacarídeos constituintes da parede celular. O arraste de mosto fermentado durante a remoção destas células do fundo do reator dificilmente irá promover o arraste de açúcares redutores, pois ao final da fermentação o meio contém reduzido teor destes compostos. A exceção para esta análise foi o trub quente, que apresentou elevado teor de açúcares redutores (20\%), o que está de acordo com sua formação durante o processo cervejeiro, cuja precipitação protéica durante a cocção e sua deposição promovem arraste de mosto.

Há poucos relatos na literatura à respeito da determinação do teor de açúcares redutores solúveis nos resíduos cervejeiros. Gencheva e colaboradores (2012) determinaram o teor de açúcares redutores presentes em bagaço de malte pelo método do DNS, obtendo resultado de $2,4 \%(\mathrm{~m} / \mathrm{m}$ de matéria seca). Segundo Priest e Stewart (2006), a deposição do trub quente promove arraste de mosto e perdas entre 1 e $2 \%$ de extrato fermentescível.

A concentração de proteínas determinada no bagaço de malte, que é dependente de fatores como tipo do cereal utilizado, adição de adjuntos, e condições de moagem e mostura, foi significativa $(26,9 \%)$. O fator de conversão de nitrogênio total em proteínas adotado para o bagaço de malte em 


\section{9 a 22 de outubro de 2014 \\ Florianópolis/SC}

diversos trabalhos revisados foi 6,25. Robertson e colaboradores (2011) e Faulds e colaboradores (2009) encontraram o teor de proteínas próximo a 18\%, enquanto Celus e colaboradores (2006) encontraram valor mais próximo ao obtido neste trabalho, 26,7\%. Para o trub quente $(48,8 \%$ de proteínas) foi adotado o mesmo fator utilizado para o bagaço de malte $(6,25)$, tendo em vista ser este a principal origem das proteínas que o compõem. Trabalhos de revisão indicam entre 50 e $70 \%$ de proteínas na composição do trub quente (Priest e Stewart, 2006; Barchet, 1993). Novamente, a composição do trub é dependente de diversos fatores, sendo diferenciada para cada cervejaria.

O teor de proteínas na levedura residual cervejeira $(52,7 \%)$ foi obtido pela utilização do fator 5,8 de conversão de nitrogênio total em proteína bruta. Vilela e colaboradores (2000) e Yamada e colaboradores (2003) também utilizaram o fator 5,8, enquanto Caballero-Cordoba e Sgabieri (2000) e Pinto e colaboradores (2013) utilizaram o fator 5,5. Estes autores encontraram o teor de proteína variando entre 35,2 e $47,19 \%$, em base seca, da biomassa celular.

Quanto ao teor de proteínas solúveis, os baixos valores encontrados para o bagaço e o trub neste trabalho podem ser justificados pela forma como estes resíduos são gerados. O bagaço é esgotado de toda sua fração solúvel durante a passagem da denominada água secundária ou de lavagem, enquanto que o trub quente é proveniente principalmente da coagulação e insolubilização de proteínas no mosto durante a etapa de cocção, resultando, ambos os casos, em materiais com baixa fração solúvel de proteínas. Já o valor mais elevado para a levedura cervejeira pode ser explicado pela possibilidade de lise celular durante seu processo de secagem, liberando para o meio material intracelular rico em nitrogênio solúvel.

\section{CONCLUSÕES}

Os três resíduos cervejeiros avaliados (bagaço de malte, trub quente e levedura residual cervejeira) apresentaram elevado teor de umidade e significativa fração protéica em sua matéria seca, adicionada de considerável teor de minerais. O trub quente apresentou elevado teor de açúcares redutores em sua fração solúvel, enquanto que a levedura residual apresentou proteínas solúveis em maior teor que os demais resíduos. Pode-se, então, admitir que devido à sua rica composição, tais resíduos apresentam-se como potencial para utilização em diversas áreas de tecnologia, como alimentação humana e animal, e biotecnologia industrial.

\section{REFERÊNCIAS}

ALBUQUERQUE, D. M. N. Resíduo desidratado de cervejaria para suínos em crescimento e terminação. Dissertação de Mestrado em Ciência Animal. UFPI, 2009.

ALIYU, S.; BALA, M. Brewer's spent grain: A review of its potentials and applications. African Journal of Biotechnology, v. 103, n. 3, p. 324-331, 2011.

AOAC. Association of Official Agricultural Chemists. Official Methods of Analysis. HORWITZ, W., Washington, D. C., 1975.

ASSIS, E. M. Polissacarídeos da parede celular de levedura de cervejaria (Saccharomyces cerevisiae), obtida por rompimento mecânico da célula e de processo industrial de autólise. Tese de 


\section{9 a 22 de outubro de 2014 \\ Florianópolis/SC}

Doutorado em Tecnologia de Alimentos, UNICAMP, Campinas, 1996.

BARCHET, R. Hot Trub: Formation and removal. Brewing Techniques, v.1, n.4. 1993.

BEKATOROU, A.; PSARIANOS, C.; KOUTINAS, A. A. Production of food grade yeast. Food Technol. and Biotechnol, v. 44, n. 3, p. 407-415, 2006.

BELLUCO, A. E. S. Alterações fisiológicas e de composição em Saccharomyces cerevisiae sob condições não proliferantes. Dissertação de Mestrado em Ciência e Tecnologia de Alimenntos. USP, 2001.

BRIGGS, D. E.; BOULTON, C. A.; BROOKES, P. A.; STEVENS, R. Brewing Science and Practice. Flórida: CRC Press LLC and Woodhead Publishing Limited, 2004. 863p.

CABALLERO-CORDOBA, G. M.; SGARBIERI, V. C. Nutritional and toxicological evaluation of yeast (Saccharomyces cerevisiae) biomass and yeast protein concentrate. Journal of the Science of Food and Agriculture, v. 80, p. 341-351, 2000.

CELUS, I.; BRIJS, K.; DELCOUR, J. A. The effects of malting and mashing on barley protein extractability. Journal of Cereal Science, n. 44, p. 203-211, 2006.

CORDEIRO, L. G.; El-AOUAR, A. A.; GUSMÃO, R. P. Caracterização de bagaço de malte oriundo de cervejarias. Rev. Verde de Agroecol. e Desenv. Sustent., v. 7, n. 3, p. 20-22, 2012.

COSTA, A. D.; MATTOS, E. S.; LIMA, C. A. R.; VIEIRA, A. A.; MATTOS, M. A.; FERREIRA, R. A. D.; SARINHO, V. C.; RAMALHO, H. F. Composição química e energia digestível do bagaço de malte em suínos machos nas fases de crescimento e terminação. Anais do Congresso Brasileiro de Zootecnia, Pernambuco, 2006.

COSTA, A. G.; MAGNANI, M.; CASTRO-GOMEZ, R. J. H. Obtenção e caracterização de manoproteínas da parede celular de leveduras de descarte em cervejaria. Acta Scientiarum, v. 34, n. 1, p. 77-84, 2012.

FAULDS, C. B.; COLLINS, S.; ROBERTSON, J. A.; TREIMO, J.; EIJSINK, V. G. H.; HINZ, S. W. A.; SCGOLS, H. A.; BUCHERT, J.; WALDRON, K. W. Protease-induced solubilisation of carbohydrates from brewer's spent grain. Journal of Cereal Science, v. 50, p. 332-336, 2009.

FERREIRA, M.P.L.V.O.; PINHO, O.; VIEIRA, E.; TAVARELA, J.G. Brewr's Saccharomyces yeast biomass: characteristics and potential aplications. Trends Food Sci. Technol., v. 21, p. 77-84, 2010.

FILLAUDEAU, L.; BLANPAIN-AVET, P.; DAUFIN, G. Water, wastewater and waste management in brewing industries. J. C. Prod., v. 14, p. 463-471, 2006.

GENCHEVA, P.; DIMITROV, D.; DOBREV, G.; IVANOVA, V. Hydrolisates from malt spent grain with potencial application in the bioethanol production. Journal of BioScience and Biotechnology, p. 135-141, 2012.

HARRISON, J. S. Yeast production. Em HOCKENHULL, D. J. D. Progress in industrial microbiology. London, Colchester and Beccles, 1971. P. 129-178.

LIMA, U. A. Matérias-primas dos Alimentos. São Paulo: Ed Blucher, 2010. 402p. 
MAN-JIN, I.; DONG, C. K.; CHAE, H. J. Downstream process for the production of yeast extract using brewer's yeast cells. Biotechnology and Bioprocess Engineering, n. 10, p. 85-90, 2005.

MUSSATO, S. I.; DRAGONE, G.; ROBERTO, I. C. Brewers' spent grain: generation, characteristics and potential applications. J. Cereal Sci., n. 43, p. 1-14, 2006.

OLAJIRE, A. A. The brewing industry and environmental challenges. J. Cleaner Prod., p. 1-21, 2012.

PANDEY, A.; SOCCOL, C. R.; NIGAM, P.; SOCCOL, V. T. Biotechnological potential of agroindustrial residues I: sugarcane bagasse. Bioresour. Technol., v. 74, n. 1, p. 69-80, 2000.

PINTO, L. C.; LOPES, M. V.; CARVAlHO FILHO, C. D.; ALVES, L. V. A.; BENEVIDES, C. M. J. Determinação do valor nutritivo de derivados de levedura de cervejaria (Saccharomyces spp.). Revista Brasileira de Produtos Agroindustriais, v. 15, n. 1, p. 7-17, 2013.

PRIEST, F. G.; STEWART, G. G. Handbook of Brewing. 2 ed. Flórida: CRC Press and Taylor \& Francis Group, 2006. 829p.

REHM, H.J.; REED, G. Biotechnology. V.3, 1st Edition, Germany: VerlagChemie, 1983.

ROBERTSON, J. A.; I'ANSON, K. J. A.; TREIMO, J.; FAULDS, C. B.; BROCKLEHURST, T. F.; EIJSINK, V. G. H.; WALDRON, K. W. Profiling brewers' spent grain for composition and microbial ecology at the site of production. Food Sci. Technol., n. 43, p. 890-896, 2010.

SANTOS, M.; JIMENEZ, J. J.; BARTOLOME, B.; GOMEZ-CORDOVES, C.; NOZAL, M. J. Variability of brewer's spent grain within a brewery. Food Chemistry, n. 80, p. 17-21, 2003.

TSCHOPE, E. C. Microcervejarias e Cervejarias: A história, a arte e a tecnologia. Editora Aden, São Paulo, 2001.

VIEIRA, M. S.; SANTOS, V. M.; VIEIRA, A. A. Composição química e digestibilidade dos nutrientes do bagaço de cevada determinados em suínos em terminação. Anais do XIII Encontro Latino-Americano de Iniciação Científica e IX Encontro Latino-Americano de Pós Graduação, Paraíba, 2006.

VILELA, E. S. D.; SGARBIERI, V. C.; ALVIM, I. D. Determinação do valor protéico de células íntegras, autolisado total e extrato de levedura (Saccharomyces sp.). Revista de Nutrição, v. 13, n. 3, p. 185-192, Campinas, 2000.

YAMADA, E. A.; ALVIM, I. D.; SANTUCCI, M. C. C.; SGARBIER, V. C. Composição centesimal e valor protéico de levedura residual de fermentação etanólica e de seus derivados. Rer. Nutr., v. 16, n. 4, p. 423-432, 2003.

ZHAOXIA, L.; JINLONG, Y.; DAN, S.; CHENG, D. Thechniques optimization of combined enzymatic hydrolisis on brewers' spent grain from Novozymes. Journal of Life Sciences, v. 6, p. 1232-1236, 2012. 